\title{
Lost in translation?, edited by Denis Renevery and Christiania Whitehead
}

Paola Cifarelli

\section{(2) OpenEdition}

1 Journals

Édition électronique

URL : https://journals.openedition.org/studifrancesi/4555

DOI : 10.4000/studifrancesi.4555

ISSN : 2421-5856

Éditeur

Rosenberg \& Sellier

Édition imprimée

Date de publication : 1 avril 2012

Pagination : 114

ISSN : 0039-2944

\section{Référence électronique}

Paola Cifarelli, «Lost in translation?, edited by Denis Renevery and Christiania Whitehead », Studi Francesi [En ligne], 166 (I | LVI) | 2012, mis en ligne le 30 novembre 2015, consulté le 19 novembre 2021. URL : http://journals.openedition.org/studifrancesi/4555 ; DOI : https://doi.org/10.4000/ studifrancesi.4555

Ce document a été généré automatiquement le 19 novembre 2021.

\section{cc) (1) $\odot$}

Studi Francesi è distribuita con Licenza Creative Commons Attribuzione - Non commerciale - Non opere derivate 4.0 Internazionale. 


\title{
Lost in translation?, edited by Denis Renevery and Christiania Whitehead
}

\author{
Paola Cifarelli
}

\section{RÉFÉRENCE}

Lost in translation?, edited by Denis RENEVERY and Christiania WHITEHEAD, Turnhout, Brepols, 2009 («The Medieval Translator - Traduire au Moyen Âge» 12).

1 Pour la plupart consacré à la traduction en moyen anglais, ce volume renferme quelques articles qui concernent aussi le domaine de la littérature française.

2 Alessandra PETRINA (Excuse my french: Bilingualism and Translation in Lancastrian England, pp. 121-131) utilise la ballade qu'Eustache Deschamps dédia au poète anglais Geoffrey Chaucer («O Socrates plains de philosophie») comme point de départ pour une réflexion plus vaste sur les implications politiques des questions liées à la langue dans l'Angleterre du début du $\mathrm{xv}^{\mathrm{e}}$ siècle, et plus particulièrement sur le rôle et la fonction du français au sein de la culture anglaise au cours du Moyen Âge tardif.

3 Caroline BOUCHER et Jean-Pascal POUZET (La Matière des "Echecs amoureux", d'Evrart de Conty à Reson and Sensuallyte, pp.157-172) suggèrent d'analyser la traduction anglaise de l'ouvrage attribué à Evrart de Conty, réalisée par John Lydgate avant 1415, à la lumière des autres œuvres du poète français et surtout en tenant compte d'une part, du Livre des eschez amoureux moralisés, et d'autre part du Livre des problemes. Cette analyse permet également de jeter un regard nouveau sur le rapport entre texte et glose dans le poème français.

4 Ludmilla eVdoкimova (Le prologue du "Livre Flave Vegece de la chose de chevalerie" et la question de son attribution, pp.173-185) se penche sur le prologue de la traduction du De re militari de Végèce, pour revenir sur la question de son attribution à Jehan de Vignay. Après avoir analysé quelques questions liées au sens de ce prologue, qui s'éclaircit par 
la confrontation avec les sources utilisées pour sa composition, l'A. montre les points de contact avec quelques passages du Miroir historial traduit par le même Jehan de Vignay, mais montre également que quelques-uns des choix de traduction semblent exclure que le prologue puisse être attribué à celui-ci. 